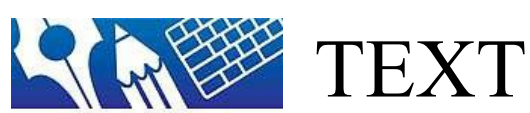

Australasian Association of Writing

Programs
Journal of writing and writing courses

ISSN: 1327-9556 | https://textjournal.scholasticahq.com/

\title{
Structural whiteness and the business of creative writing in Australia: Developing reflexive pedagogy \\ Bonny Cassidy
}

To cite this article: Cassidy, B. (2020). Structural whiteness and the business of creative writing in Australia: Developing reflexive pedagogy. TEXT: Journal of writing and writing courses, 24(1): 1-20. https://doi.org/10.52086/001c.17810 


\title{
RMIT University
}

\section{Bonny Cassidy}

\section{Structural whiteness and the business of creative writing in Australia: Developing reflexive pedagogy}

\begin{abstract}
: [1]
Two decades in my academic discipline have accreted a strata of assumptions within my practices. Most of these are about knowledge: its source in me and my informants, its places and modes of production, and methods or processes for its communication. From these have grown assumptions about myself within the discipline: the extent of my expertise, and others' expectations of it; and its relationship to other elements of my life. I take responsibility for these assumptions, however, I also understand them to be intimately connected to the cultural systems of knowledge in which I have been brought up as an Australian academic. In this discussion I contextualise how, when provoked, our discipline of creative writing reveals its local, systemic contingencies. Using my experiences within RMIT University's Bundyi Girri program as a launching point, I reflect on the ways that non-Indigenous awareness of historically excluded sovereign knowledges provokes the discipline and how recognition of these might look through the practices of the academy. I argue that reflexivity is a tool for structural change, and that it can be focused and fostered through pedagogy. To illustrate this, I share some process notes from my own recent teaching and learning. The questions that preoccupy me are: What is the readiness of creative writing as an academic discipline towards acknowledgement of sovereign knowledges? How does working within sovereign relationships differ or distinguish itself from cultural awareness or from 'Indigenising' curriculum? How is my expertise and authority as a creative writing practitioner challenged by this acknowledgement?
\end{abstract}

\section{Biographical note:}

Dr Bonny Cassidy is Lecturer in the Bachelor of Arts (Creative Writing) within RMIT University's School of Media and Communication. As a professional poet and writer, Bonny has received numerous awards and grants and her work is published widely locally and overseas.

Keywords: pedagogy, creative writing, Indigenous literature, critical whiteness 
This article was developed on the unceded lands of the Boon Wurrung and Woi Wurrung language groups of the eastern Kulin nations, where I work in the creative writing program at RMIT University, Melbourne. It was also written on the unceded land of the Dja Dja Wurrung, where I live in Castlemaine, central Victoria. I'm a fifth-generation settler of IrishAnglo-German descent, a poet and essayist, critic and editor, and scholar of Australian literature. I've been teaching the practice of creative writing and the scholarship of literary studies in universities for fourteen years.

While my writing career has taken me all over the world, I've spent more than half of my life working in Australian higher education. Like many Australian academics, that means stints across multiple institutions; for me, seven universities in two states. In this article I draw on my experience of the academic discipline of creative writing, and to a lesser extent, literary studies, as well as others' views from industry and scholarship.

Two decades in my academic discipline have accreted a strata of assumptions within my practices. Most of these are about knowledge: its source in me and my informants, its places and modes of production, and methods or processes for its communication. From these have grown assumptions about myself within the discipline: the extent of my expertise, and others' expectations of it; and its relationship to other elements of my life. I take responsibility for these assumptions, however, I also understand them to be intimately connected to the cultural systems of knowledge in which I have been brought up as an Australian academic. In the following discussion I'll contextualise how, when provoked, our discipline of creative writing reveals its local, systemic contingencies. I will then argue that reflexivity is a tool for structural change, and that it can be focused and fostered through pedagogy. To illustrate this I'll share some process notes from my own recent teaching and learning.

\section{Structural whiteness in creative writing}

The discipline of creative writing is recognised for its partial adjacency to academic systems of knowledge. Dianne Donnelly celebrates the way that it is a 'growing professional body of knowledge', thriving because its praxes are 'guided by writerly and readerly processes of creative writers' (Donnelly 2012: 5). These are constantly changing sources of knowledge that flow internationally, across media and through the influence of industry concerns. I love how inventive, resourceful and irreverent this discipline can be; and how practitioners in other disciplines enjoy a somewhat naive view that creative writing academics seem to be the playful children of the academy.

It's no coincidence, perhaps, that these observations also describe a popular and outdated cliché about Australians. As with images of national identity, however, collective assumptions about a discipline can survive longer than they should. They become internalised and, inside the matrix of academic work, pressures to maintain the status quo can exclude or suppress more complex and timely realities. 
'What I found at university was a mass delusion,' writes Bobuq Sayed in Overland, 'a nostalgic daydream about rural and suburban Australia that made little to no mention of the impact that minorities continue to make on the literary landscape of this country and the world' (Sayed 2017). I feel a bit sick when reading Sayed's disappointment with the discipline, its claim to currency and the ways it is framed. Their experience represents a missed opportunity to engage a student's critical and creative mind. Moreover, it threatens to remove that mind from the industry which is shaped by academic norms. 'If the Australian literary and publishing community is attempting to rectify its structural whiteness,' Sayed suggests, 'it must start by looking at the sites where the formal training of creative writing is occurring' (2017).

From an academic's point of view, Natalie Kon-Yu points out the continuity of power structures from academy to industry:

The further I scramble up the academic ladder, the more rarefied the air becomes. I might be the only one in meetings with a surname like mine or the only one with dark skin... The publishing industry is another white space... And what has become evident to me is that the inherent whiteness of the industry - from academia to publishing houses to editors and agents - means that we still see diverse writers as exotic, marginal and absolutely representative of their race or ethnic background. (Kon-Yu 2017)

Sayed's and Kon-Yu's experiences show that the current academic practice of creative writing cannot really be leading the Australian industry of writing, editing and publishing as it ought. Rather, the academy and industry seem to be in a feedback loop. Recently, it feels as though industry is taking the lead and the academy is desperately running to catch up. At the 2019 Australasian Association of Writing Programs (AAWP) Conference, Gomeroi writer and scholar Alison Whittaker gave a keynote address concerning the experience of First Nations students in creative writing programs. Solidarity and belonging, she explained, were increasingly more available in non-institutional environments than at university. 'Do something with your Acknowledgement,' she urged the crowd of academics and postgraduates (Whittaker 2019). Earlier in her career, she stated in an interview that, 'If I were to talk about decolonisation with reference to [my poetry], I would talk about Aboriginal women passing on knowledge and deliberately evading the academy with it' (Sullivan 2016).

Creative writing is as affected by cultural and social biases as any discipline. Donnelly reminds us that 'methods of pedagogy are driven by a teacher's perception of where meaning lies in the context of the writing process. What a teacher privileges as it relates to text, writer, reader and reality (as an implicit or explicit world-view) is tied directly' (Donnelly 2012: 18) to all aspects of her teaching approach. The field of critical pedagogy has investigated this relationship of worldview to method. For example, Paulo Freire's model of dialogic pedagogy identifies the way humans change our perception of knowledge. In Freire's words, 
'Human beings are because they are in a situation... Reflection upon situationality is reflection about the very condition of existence' (2000: 109). Freire developed his theory from and for those teaching and learning under conditions of oppression. Critical pedagogy seeks to intervene on where meaning lies in dominant systems of knowledge. In their accounts of creative writing learning and teaching experiences in Australia, Bobuq Sayed and Natalie Kon-Yu do indeed identify a dominant system, as well as a gap that has formed between the knowledge produced by that system, and the situation of its participants. The gapis not seen from within the structurally white academic system, yet it is seen by writers and readers whose practices lie at least partly outside. What's arresting is that, as Donnelly pointsout, these two positions overlap in creative writing. Such dissonance, I feel, is unique to the discipline. What seems to have created the gap revealed by Sayed and Kon-Yu is a widespread absence of reflection.

As the structures that store and produce knowledge, higher education and academic practice in Australia are some of the most important settler colonial institutions. Exclusion is the name of the game. Education pedagogues Samantha Schulz and Jennifer Fane argue that 'excising race from our core discussions as Australian educators is reflective of a broader culture of whiteness characteristic of Australian tertiary settings' (2015: 137). They develop Freire's theory for an Australian context by placing emphasis on the situation of those who represent and actively perpetuate the institution: academics. 'For education to be a basis for equitable social change, we believe that teachers first must be made aware of these relations [of social difference] and of their personal relationships to them' (Schulz \& Fane 2015: 137).

Who will make us aware? Teachers are those who represent the discipline to students and peers, but they do much more. In the context of Australian universities, the role of 'teacher' (lecturer or tutor) can also sit within a workplan that includes the roles of course coordinator, project or discipline leader and administrator, supervisor and researcher. Some teachers will be promoted to staff the bureaucratic and corporate leadership levels of universities. The expected simultaneity and continuity of such roles means that, even when employed sessionally, academics exert power across many levels of work in universities. However, even when 'teacher' means solely design and/or delivery of coursework and assessment - as is the case for much of our gigantic sessional teaching workforce - this role is empowered to directly shape and impact the values of the discipline's student body. That means empowering industrial, cultural and civic values through graduates.

It's easy to see how a disciplinary 'mass delusion' might thrive in this environment. Under our noses (and in our hands), the academic discipline of creative writing is transitioning from the spiky young adult of the Australian academy, to the comfortable fogey. If academic disciplines are to fulfil their public role of leading innovative practices and ideas, the 'broader culture of whiteness' (Schulz \& Fane 2015: 137) in Australian universities demands work by all academics at all levels. In creative writing, our ability to lead writing, editing and publishing will only be enabled by each of us reflecting on our own situationality within the local history of the discipline. 
It is hardly a controversial view that posits the structure of colonisation as the foundation of structural whiteness in Australia. Imperial dispossession of First Nations established a settler colonial state that has dominated systems of knowledge in order to perpetuate itself. This required the active exclusion of First Nations peoples and knowledges, and has constructed a 'regime of race' for all settlers (Wolfe 2016: 3). The attempted elimination of First Nations sovereignty has created a repression that continues to 'return' throughout settler colonial politics, culture and society (Wolfe 2016: 31-33). Goenpul scholar Aileen Moreton-Robinson notes that 'white possession is the common denominator we all share' and that the possession of First Nations lands is the 'anchor' that grounds all resulting forms of settler colonial hegemony (Moreton-Robinson 2015: xix-xx). Critical whiteness scholar, Fiona Nicoll also emphasises the shared nature of colonial legacy: 'The legacy of Terra Nullius sticks to our shoes with the dirt as we walk over Indigenous sovereignties every day ... regardless of the individual and family migration trajectories that have brought us to this place' (Nicoll 2004).

For us writers, researchers and teachers of writing, our media are those most heavily relied upon to enact this domination and perpetuation. The construction of narrative (what's told, what's not), the distribution of point of view (who tells, who is told), the erasure of one language for another (how to tell, how to make sense), the invention of image and symbol (what is like, what is other), and the very power of voice (to speak, to write, to see) that embodies all these acts, are the key social and cultural tools of colonisation and colonialism.

On the flipside, they are also the tools of memory, dissent and change. In his creative writing PhD completed at RMIT, Tony McMahon's dissertation was titled, 'Remembering to forget: writing and healing in the Australian novel'. In it, McMahon suggests that: 'Creative writing as it is taught in our universities could ... conceivably be at the forefront of a larger social movement centred around the notion of speaking well and remembering properly' (McMahon 2015: 267). That larger social movement of Reconciliation between First Nations and settlers is partly predicated on truth-telling about the past and the present. How can the discipline of creative writing respond to this need?

While the structural exclusivity of creative writing affects the vast population of Australians not entitled to the privilege of whiteness, the calcification of the discipline experienced by Sayed, Kon-Yu and so many others will only be unsettled when more non-Indigenous practitioners can reflect on their situation within Australia's foundational exclusion of knowledges. At present, sovereign knowledges are actively and notably contributed to the discipline by First Nations writer-academics. There are also plenty of non-Indigenous academics who have incorporated an increasing amount of First Nations writing and writers into existing courses. However, as a minority in the discipline of creative writing in Australia, the work of First Nations practitioners, researchers and teachers is too regularly positioned as 'exotic, marginal and absolutely representative of their race or ethnic background' (Kon-Yu 2017), rather than as central to the practice of the discipline. This is perpetuating a deficit in First Nations education. Wiradjuri poet and academic Jeanine Leane highlights 'the link between the lack of Aboriginal voice and representation within the curricula and the higher 
attrition rates among Aboriginal students' (Leane 2016). However, as she goes on to point out, marginal academic representation is also perpetuating a deficit in non-Indigenous creative and critical depth and range:

[I]f non-Indigenous people are still only encountering Indigenous people via the works of non-Indigenous writers/historians/filmmakers/artists, then are they really encountering us at all? How can they even think about writing about us if you don't really know us? (Leane 2016)

Addressing the deficit of First Nations employment in the academy is not enough. Indigenising our curricula is not enough.

At this point in time, critical whiteness theory is a growing field in the Australian academy, and it has interacted with creative writing through a series of key texts that combine autoethnography, fictocriticism and poetics [2]. This small body of work has sought to provoke readers and writers to reflect on the relationship of language and writing forms to colonisation and colonialism. It seeks to decentre settler colonial assumptions about invisible authorship and demand accountability for subjectivity and voice. It also forges new forms of expression to fit the purpose of destabilising social, historical and theoretical certainties of settler identity. However, critical whiteness is a field and as such it is occupied by those who commit to its scholarship. In other words, 'speaking well and remembering properly' (McMahon 2015: 267) is currently still the work of a few in the discipline - a special interest, even - rather than the historical, lawful and institutional business of all.

\section{The business of creative writing}

In my institution, RMIT University's Reconciliation Action Plan (RAP) accounts for this situation in the academy as a fragment of the wider social condition. It frames the work of Reconciliation as an opportunity missed by and denied to many non-Indigenous Australians (RMIT University 2019: 12); an opportunity therefore missed by academic disciplines. The RMIT Act enshrines social justice within the objects of the university as a public institution (RMIT University 2010, Part 2 Division 1: 8). This means that the university is bound to address the social inequality of settler colonialism.

A couple of years ago I became involved in a new program within RMIT University's RAP. In what is now an expectation across many universities, First Nations cultural awareness training has become a mandatory professional development activity for all academic and professional staff. The program at RMIT, named Bundyi Girri, is designed to follow cultural awareness training (facilitated by Koori Heritage Trust, in RMIT's case). Its mission is to support non-Indigenous staff into an awareness of their role and ongoing responsibility in relation with First Nations peoples. Not only is it distinguished from the 'compliance' nature of cultural awareness training, it also branches off the university's Reconciliation work on 
social and educational deficit, to create an adjacent focus on cultural and disciplinary potential (RMIT University 2019: 12). Ultimately, its goal rests on Moreton-Robinson's argument that "what is required is scholarship that engages with the traditional disciplines in order to demonstrate how this knowledge is limited in its ability to understand [First Nations peoples]' (Moreton-Robinson 2015: xvi).

Bundyi Girri is a phrase from the Wiradjuri language, meaning 'Shared Futures'. The program was established by Wiradjuri man, Professor Mark McMillan, formerly Deputy Pro Vice-Chancellor Indigenous Education and Engagement, and Chair of Academic Board at RMIT, and by Peter West, an academic in communication design at RMIT, whose scholarship in critical whiteness has developed frameworks for embedding First Nations sovereignty into tertiary curricula. The essential prompt that grounds Bundyi Girri workshops and discussions is an invitation by the Traditional Owners of Melbourne, the Boon Wurrung and Woi Wurrung language groups. Wominjeka translates roughly to What is your purpose, what is your business? This greeting invites the guest onto Country and asks for their standpoint. In the context of the academic workplace, Wominjeka goes to the heart of speaking well and remembering properly.

I now want to explore the ramifications of this invitation for my practice of creative writing, and then consider that as a context for pedagogy. Using my experiences within the Bundyi Girri program as a launching point, I reflect on the ways that non-Indigenous awareness of historically excluded knowledges provokes the discipline; and how recognition of sovereign relationships might look through the practices of the academy. This reflection is partly based on my own pedagogy and research; other parts are gleaned from conversations both formal and informal with colleagues at RMIT and other creative writing programs. And yet other aspects draw from burgeoning scholarship in the application of critical pedagogy, global indigenous research methods and critical whiteness to creative writing. I will also raise more questions to which I currently have no answer: queries and speculations that will take time and development for myself and peers to evaluate. These provide the basis for some pedagogical speculations I have recently initiated and will mention in the final section of this article.

Tony McMahon (2015) contributes two goals for the creative writing discipline: the first, remembering properly invites me to consider where First Nations knowledges have been excluded, that is, forgotten by the practice of creative writing studies and pedagogy; the second, speaking well provokes me to reflect on how respectful relationships with that knowledge might be better established and nurtured in and through creative writing.

My own experience of working with sovereign practices in academic teaching, course coordination and project leadership has until recently tended toward listening to First Nationsperspectives and making space for their self-presentation. These include invitations to guest speakers, alumni and industry mentors, and coordination of writersin-residence for five years. All of these activities have been designed to engage students and, increasingly, public audiences with writing, performance and mentorship by First 
Nations writers. My aim has been to create opportunities for these writers and their work to appear within undergraduate curricula, and for their expertise and experience to offer leadership to First Nations and non- Indigenous students alike. The outcomes of these activities have all been valuable and, in general, feedback from participants positive and constructive. However, as I more deeply reflect on the relationship of these outcomes to other areas of my disciplinary practice, I see that they have either occupied a sidebar to the rest of my course contents, or have been largely un-contextualised for audiences and students except by the guest writers themselves. Ultimately, the central discourses of non-Indigenous writing craft, critical reading traditions and listening skills - not to mention approaches to event organisation and hosting - have been left intact. Assimilation in this context can be achieved by exclusion: a First Nations guest might visit for one lecture, the lecture might be held outside of class hours, the guest's topic is suggested to them, the venue is a traditional campus one, the predominantly white academic audience listens passively. Not only may this not be a culturally safe context for theguest, but the audience has not been invited to examine their own comfort zones around how their knowledge is practiced. And while my own expertise and authority has been challenged,this has happened in the forms of hard-learned lessons and personal reflection, rather than as a deliberate, structured and informed decentring of my workplace habits.

In wanting to develop these reflections further, I turn again to critical pedagogy for some ideas about difference and multiplicity of systems, rather than consumption and assimilation into the socially dominant one. North American pedagogues Joe L Kincheloe and Shirley R Steinberg have written about their efforts to 'expand a form of critical multilogicality' (2008: 135). This is an 'intercultural/interracial effort to question the hegemonic and oppressive aspects' (Kincheloe \& Steinberg 2008: 135) of one's discipline, so that it may expand to contain multiple ways of thinking and doing. In curricula designed for predominantly First Nations communities, two-way learning is an established pedagogical methodology. Australian cultural studies/linguistics scholar Michael Christie uses the alternative term 'transdisciplinary' to describe research and teaching that combines bounded or distinct knowledge systems and traditions (2006: 88). A transdisciplinary approach to knowledge traditions 'moves beyond the disciplinarity of the university and takes into account knowledge practices which it will never fully understand' (Christie 2006: 88). Christie's use of transdisciplinary acknowledges the gap between knowledge systems, rather than seeking to smooth it over.

This is a rich understanding of where meaning lies for creative writing academics and students alike. What assumptions about meaning might continue to inflect the texts we nonIndigenous disciplinarians choose to set as teachers, and our field of reference as supervisors; the contexts we do or do not examine in course design, the traditions of craft we emphasise, and the ones we do not encourage? Indeed, actively framing creative writing as already in (interdisciplinary) dialogue with other knowledge systems might be a start. Michael Griffiths has explored this positioning in the study of Australian Literature [3]. But the challenge to 
disciplinary definition is not the only one: sovereign knowledges provoke the disciplinary expertise and authority of non-Indigenous academics.

Authority is important to academics' notion of our professional and cultural business. We are expected to - and expect ourselves to - constantly conduct a performance of expertise in setting meeting agendas, appearing at a lectern, assessing the quality of student work, examining theses, appearing on radio, peer reviewing and publishing ideas. So can we let these expectations go when it comes to understanding and communicating the limitations of our knowledge? Can we find additional strategies to knowing, or to obtaining knowledge?

In conversations with colleagues about practising relationships with sovereign knowledges, I hear anxiety. I have felt it myself. Non-Indigenous academics panic, as they see the depths of not-knowing open up beneath their feet. But I don't know enough about that. I could never teach that. We need to find out more before we can talk about it. The impulse to research is not in itself a bad thing; respectful listening and curiosity demonstrate an investment in deepening lived and learned knowledge rather than stereotypes, generalisations, guesses, objectifications or quizzing. But first I need to release my academic self-expectation of being one who needs to deliver information and one who needs to assess conclusive success. How else can I guide enquiry?

Jill Abdullah and Ernie Stringer suggest giving up 'the search for the foundations of knowledge and the quest for certainty' (1999: 154-155). As a result, the emphases of research, learning and teaching become about defining the conditions for communicating and gathering knowledge (Abdullah \& Stringer 1999: 154-155). In this regard, the influence of autoethnography on creative writing has been a strong one. It has introduced a way of seeing disciplinary knowledge as a question of how as much as what:

It is a challenge to compositionists, writing teachers, and all teachers, to intervene into the ethnographic project as it is variously manifested in our cultures and curricula, and to conceptualize this intervention as a question of writing as much as it is a question of history, politics, and sociality. (Barnard qtd in Tombro 2016: 9)

In Australia, autoethnography accompanies the field of practice-based and practice-led research methodology in informing creative writing higher degree research. But these fields also offer a ready resource for undergraduate teaching as well as project and program leadership. Too often, though, we keep these groups of students and types of work separate from one another. As it is, the central pedagogical method of undergraduate workshopping places emphasis on a teleological improvement of craft; similarly, our constant focus on the publishability of student work might be counterproductive when we consider the limitations of the industry highlighted by Sayed and Kon-Yu. Perhaps, Catherine Cole suggests, 'the most important part of the creative process may not be the creative product at all, but rather may well be the framing, discovery, or envisioning of the creative question' (Cole 2007: 5). In regarding sovereign knowledges, non-Indigenous academics may be able to encourage lessrisk-averse non-Indigenous students in creative writing if we teach reflection as an 
equal or superior criterion of academic success to that of timely polish (Cole 2007: 7).

\section{Developing reflexivity through pedagogy}

Using privilege to leverage spaces in the academy for First Nations practitioners is essential to structural change. But the larger movement of remembering properly and speaking well is not as passive as making space; it has to also be about how we non-Indigenous teachers and learners reflect (remember) and express (see) ourselves in relation to that knowledge. Gary Howard captures the challenges of redirecting academic structures into developing ethics and practices of power-sharing:

Such a change will require the mobilisation of tremendous political and financial resources, resources which for the most part are in the hands of European descendants in the many nations of the West. Once again, the primary burden for this shift in perspective and power should not be the sole responsibility of indigenous people. They can and should provide the content, the perspectives, the traditional pedagogy and the cultural legitimacy for the change. However, creating the political will to shift the educational paradigm away from cultural dominance ought to be the particular responsibility of those of us who have seen the painful and destructive consequences of our own Eurocentric educational practices. (Howard 1999: 235)

Cultural awareness is a foundation but not an end point in this journey for non-Indigenous academics. In the following section, I want to suggest that the development of reflexive pedagogy is needed to lead cultural change from within the discipline. While I continue to reflect on structural limitations and contingencies of the academy that currently define the renovative potential of creative writing, the power of pedagogy is able to make incursions on these in discipline-appropriate and culturally specific ways. I will illustrate some of my own recent teaching and learning experiments that seek to begin developing a reflexive pedagogy towards sovereign knowledges.

In my work at RMIT, the exercises that Bundyi Girri deploys are prompted by the Kulin invitation, Wominjeka. To reply to this greeting I must reframe my academic identity through place, heritage and the position of guest (as I did in the introduction to this article). In doing so, I respectfully fulfil a cultural protocol; in negotiating another system of identification, I discover new sites of subjectivity to express. Moreover, this custom requires me to collapse the obligation of the citizen into the role of the academic, thus suspending the institutionally bounded authority that I carry about. Bundyi Girri work requires participants to articulate a statement about how they relate to their discipline, such as what they see as the main responsibilities of their job, what they see as their specialisation, and how this extends from their ability to name the land on which they live and other places they might have grown up or worked. It can be surprising and illuminating to see non-Indigenous academics struggle with this task. I've noticed that, in these discussions, academics of colour tend to compose a 
story of themselves more quickly and specifically than the majority, perhaps because they have been asked to deliver it on a regular basis. For other settlers, we struggle to get beyond 'white', or resist referring to our white European heritage out of shame.

Deploying 'elements of Indigenist research', Noonuccal woman Karen Martin describes the importance of introducing one's standpoint before engaging in dialogue with First Nations peoples and knowledges. This method is one that we non-Indigenous academics may reflect and adopt in ways appropriate to our work including teaching. 'In providing these details,' says Martin,

I am claiming and declaring my genealogy, my ancestry and my position as a researcher and author... As a researcher, this clearly presents the assumptions upon which my research is formulated and conducted. This also allows others to locate me and determine the types of relations that might exist. (Martin \& Mirraboopa 2003: 204)

I'm interested in how we might model this as teachers of creative writing. In 'Decolonising the reading of Aboriginal and Torres Strait Islander writing: reflection as transformative practice', Sandra Phillips and Clare Archer-Lean share their trans-cultural work on constructing appropriate teaching strategies for reading First Nations texts. Drawing from Indigenous research methodology, they place the texts at the centre of the learning experience and design from them, rather than incorporating them into an 'Indigenised' syllabus. They put it this way: 'First Nations agency through writing leads curriculum design' (2019: 25). In relation to this, 'writing is the learning environment authority', not the teacher (Phillips \& Archer-Lean 2019: 25).

What particularly interests me about this account is that it makes room for academic vulnerability. It addresses the shakiness of Western academic expertise directly, by positioning the teacher as a fellow reader and shadowing interlocutor or facilitator to the student, instead of as an authoritative guide (Phillips \& Archer-Lean 2019: 29). As Phillips and Archer-Lean explain, they aim 'to shift the study of Aboriginal and Torres Strait Islander writing away from post-colonial reading into decolonising reading' (2019: 26). Without a teacher who is reflective of their own standpoint and its implicit assumptions, what Phillips and Archer-Lean have constructed could not be attempted:

For our purposes, colonising encounters are those moments, situated within the English tertiary tutorial or individual assessment that make assumptions about the meanings and context of First Nations writing drawn from unquestioned "norms" and hierarchies of genre or writing conventions and cultural stereotypes. They arise, primarily, from the unexamined privilege of non-Indigenous students. They are those "close readings" that seem to focus only on the text yet are drawn more from a preexisting set of cultural understandings and do not consider the broader context of the writing. (Phillips \& Archer-Lean 2019: 26) 
Their standpoint approach reinforces Barnard's and Cole's ideas about reflexive and autoethnographic creative writing methods. In Phillips and Archer-Lean's course, 'students were assessed not only on their own initial close critical reading (observations of literary devices and impressions of the meaning)' but also on two further tasks:

(a) articulate their own speaking position and reflect on whether initial impressions were influenced by that speaking position;

(b) consider what other factors outside the text they may (or may not) have accounted for, including worldview, and research into the factors affecting the distribution, reception and production of writing. (Phillips \& Archer-Lean 2019: 28)

In 2019 I attempted a standpoint-based exercise in a third-year undergraduate creative writing course. The course as a whole was focused on exegesis, specifically on developing each student's articulation of a contextualised creative purpose, methodology and community of practice as emerging writers about to enter industry. I developed a class-based task for the second week of semester, in which the course learning objective of exegetical articulation was to first be done in relation to Kulin lands. In other words, a place-based consciousness (for the majority of students, also a settlement-based consciousness) of knowledge was to be the foundational way that students contextualised their writing practice to themselves and others. The task asked students to consider their writing in relation to the Kulin seasonal calendar, a piece of information that was accessible via an installation on campus. By noting what the calendar revealed they did and did not know about the locality of their writing, they were able to situate what they did and did not know about their practice. For example, if a student knew they wrote best when the summer temperatures cooled off (iuk), had they noticed that the mornings were darker but the evening light was still long at that time? If they had, did that seasonal feature in the Kulin calendar influence their writing habits? If they hadn't noticed, why not; was there something else about this season that influenced their work? How could they articulate this as a practice-based relationship to the Melbourne area that included awareness (not appropriation) of Kulin knowledge?

I am in the early stages of piloting this type of pedagogical experimentation in my own courses. Thus far I have deployed contained, non-assessable creative and critical tasks, and evaluated these through surveying participating teaching staff and students, to build a range of data for pedagogical research and development. I will therefore resist measuring the success of the above activity as a case study here. Instead, I would like to highlight the significance of collegial collaboration in delivering it. I designed the activity above and contextualised it within the first two lectures of the semester, but it was delivered in class by two sessional tutors, one of whom will coordinate and lead the next delivery of the course. This tutor distilled the student response to the activity prompt, saying that the class group came to see that:

[T] here are ways to consider the gifts of having a complicated (and sometimes troubled) relationship to place. That is, that it might make us sensitive, considered ... that we might listen deeply or pay attention differently. And how these sensibilities 
might inform our writing too (Anonymous 2019).

I will now be able to work with this new coordinator on developing the activity further so that it becomes a shared pedagogical project; ideally, the task objective will become embedded in the course learning objectives, rather than being the passing interest of a rotating coordinator.

With academic structures in mind, what strikes me about these initiatives is that they require two things to be resourced by the institution: time and relationships. The collaboration between Archer-Lean and Phillips took years to develop: from Archer-Lean's doctoral study and Phillips' industry experience as an editor; to a course audit together, moving away from Indigenising content, to a mentor-mentee relationship underpinned by Archer-Lean as nonIndigenous academic in consultation with Phillips' academic and industry knowledge as a First Nations woman. 'Decolonising curriculum requires decolonising the working relationships between Indigenous and non-Indigenous academics,' writes Phillips (Phillips \& Archer-Lean 2019: 30). What does this mean for existing academic workplans? For the time and resources apportioned to course coordination, documentation and evaluation? What does it reveal of non-Indigenous assumptions about teaching capability; and about the time and professional development required to develop respectful and appropriate collegial relationships?

In the case of my teaching activity in the third-year course, it is part of an iterative, staged development of pedagogy within an entire degree program. As Bundjalung scholar and author Evelyn Araluen points out, 'decolonial' approaches towards creative writing cannot just be 'safely contained within the classroom, in the form of critical frameworks, unsettling questions or creative-thinking assessments' (Araluen 2017). Developing a reflexive pedagogy towards colonial knowledge production requires research resources, and professional development opportunities for sessional staff, as well as supportive heads of discipline in order to continue developing its relevance to community and industry. Teaching academics must be enabled to develop workplans that include these stages of development: 'A key lesson is to work slowly and allow new ideas and practices to emerge here and now, and grow slowly through mutual respect and a history of shared experience' (Christie 2009: 32). Change through pedagogy then also demands more collaboration with one another as nonIndigenous peers on a pathway together. Making time for more talking is a simple and desperately needed circuit-breaker in our cultural condition of settler colonialism. I consider my discipline team at RMIT to be particularly active in research, scholarship and engagement with First Nations literary culture and industry. However, as a discipline practice, our activities have been ad hoc and individually led. In this sense they are typical of academic workloads but also of the discipline's autonomous and hermeneutic character. We nonIndigenous staff need to develop new ways of communicating with each other to advance creative writing's relation with sovereign knowledges and practices.

These questions return to the anxiety of authority. In our work as supervisors and teachers, creative writing academics do not traditionally work in the collaborative research and enquiry methods associated with STEM disciplines. If we are to embrace our own not-knowing in the 
presence of sovereign knowledges, however, part of developing a reflexive mode of teaching and learning requires being vulnerable before one another, including students. The diversity of cultural heritage and identity we may represent as non-Indigenous disciplinarians is vast. The discourse of whiteness, if engaged with superficially, can seem to problematise only those who identify as not-of-colour. In addressing sovereignty, all settlers share the opportunity to re-learn and reconstruct our disciplines in relation with First Nations knowledges. To what extent can the task of decentring the discipline really be an autonomous or a homogenous one? How might we consider the opportunity to destabilise our discipline boundaries together? How might we assist each other to recognise and dismantle our deflective habits?

As a teacher I have presented my own creative work to my students, of course, but presenting my position as a guest on Kulin lands was different. I decided this would be a suitable basis for a teaching activity with first-year creative writing students, most of whom are unfamiliar with the physical campus, one another and their teaching staff. Again in 2019, I tried to collapse these three forms of introduction into a simple creative task. A colleague had produced audio recordings of some Kulin histories, performed by Boon Wurrung elder-inresidence at RMIT N'arweet Carolyn Briggs, and constructed them into a soundwalk app that could be used on campus (TIMeR). The walk also included a layer of stories by nonIndigenous contributors, who had each been invited to compose a response to a selected piece by N'arweet Carolyn. I was fortunate to be included in this layer, for which I recorded a short nonfiction piece I'd composed about a location in Port Phillip Bay. For me the writing task was provocative and challenging, and hugely enjoyable. Not only had I been able to listen deeply to the transmission of a Kulin history and learn from it, but I had been able to reflect that history as the orientation point for my own narration.

The soundwalk resource, already publicly available when my course commenced, seemed like the ideal grounding for the first-year experience. In their first couple of weeks as creative writing majors, students were not assessed but were required in class time to take the soundwalk, select one of N'arweet Carolyn's stories and interrogate what it revealed about their own history, identity and knowledge about the immediate environment of Melbourne where they had chosen to study. In particular, they were encouraged to compare and reflect on multiple ways of seeing place and to reassess their own assumptions about their environment. This was a transdisciplinary learning experience, in Christie's sense; the students were hearing a contemporary form of Kulin oral history, therefore learning a discipline of listening alongside their verbal capacities as creative writing students. They were also accessing two languages and considering genre boundaries around forms of nonfiction. N'arweet Carolyn's agency as elder and storyteller was therefore asserted through the stories and defined the conditions for how the students would receive them.

As listeners the students also encountered me as a non-Indigenous peer, navigating an encounter with sovereign place and knowledge through my narration on one part of the soundwalk. 'The value and success of this work come from students being encouraged to 
engage in the same kind of writing that teachers and scholars in the field are doing,' writes Melissa Tombro (2016: 9). By not assessing the students, I removed the possibility of their anxieties about correctness; instead, their written responses became material for class discussion. If they chose to share their work aloud, it also became the students' first encounter with one another as creative peers; this created a second level of close listening, and belonging to discipline, through the common experience of knowing more complexly about where and who they were as a community of writers.

After the course ended, I issued an open invitation for any of the first-year students to continue working on their written responses to the task, as an opportunity to continue a dialogue together through craft. As a result, I met with two non-Indigenous undergraduates for coffee and to develop their articulations of reflections, standpoint and purpose through form and language. Both students worked on their drafts for about three months, producing up to six versions, whenever they had time. We shared drafts with the audio walk producer and integrated her feedback on voice. In this exchange, lifted out of course-based timelines or briefs, and even out of the pressure of the formal class group, I was able to meet the students for a collaborative exploration of what our writing could do in response to Kulin knowledge. While we often seemed to be focusing on craft, what we were really exploring together was the purpose and nuance of the writing act in relation to another cultural system: a dialogue about what was authentic to their experience and access as settlers. After the experience of being a learning listener to the oral history, the equality of this process proved to be my favourite aspect of the entire activity. The outcome for these students also proved to be rewarding, as the producer offered to add their final pieces to a future layer of stories in the audio walk production. Quite possibly, future first-year students will be able to listen to these additions as they undertake the walk.

How do we compare such reflexive vulnerability and experimentation in teaching and learning against academic capabilities and indicators? These are structural accommodations, but also ontological ones. What value can we measure in failure as well as success? How do we make strong cases for iteration, development and duration? We may find ourselves guiding our teaching away from modes of self-expression and towards questions about the social value of writing, for example. Qualitative enquiry concerns the use of social study in creative writing pedagogy. Research, fieldwork or the contribution of writing to public life are examples of this methodology at work. Informed by ethnographic practices, qualitative enquiry positions creative writing as a discipline within the students' broader community andcan create an ongoing archive of student work to further advance the discipline:

Bringing experiences and multiple methods of knowing into classroom research can help expand their understanding of their communities and themselves. Also, understanding what goes into the creation of the texts they read from other authors can help them gain the necessary authority to create valuable texts. (Tombro 2016: 68)

But there is a further question to bring to qualitative teaching and learning in relation with 
sovereign knowledges. Indigenous research methodology asks, who does this work benefit? This question can be applied to every aspect of academic work including teaching (see Tuhiwai Smith 1999). Creative writing pedagogy can no longer be justified as an end unto itself, that is, by some neutral, teleological destination called 'knowledge'. Nor can it be justified by the commercial business of the university. And so, reflexive and qualitative methods of teaching and learning need to be responsive to the agency and conditions of First Nations production and practice, and the sociocultural demands of the industry that is informed by knowledge produced in the academic discipline. Ideally these should realise the broader academic and institutional structures of change that reflect the social purpose of the public institution.

In seeking to evaluate and develop a reflexive pedagogy, I will need to establish iterative ways to measure how well this teaching and learning is preparing graduates of the discipline to enter a flourishing industry of First Nations textual production. Ballardong Noongar writer Timmah Ball emphasises that First Nations meaning-making must be central, rather than token or marginal in organisational structures and initiatives:

[I]t is imperative that these processes are framed around Aboriginal values, rather than expecting Aboriginal authors to mould their thinking to suit white western views... We must continue to break industry boundaries, pushing for greater Indigenous representation in leadership roles, as well as fostering a culture of Indigenous-led and controlled initiatives throughout literary culture. (Ball 2018)

That is the culture for which I am preparing my students as creative citizens; how well and in what ways will they contribute to it?

Another ongoing goal in this process of development has to be the specificity of approach to First Nations perspectives through pedagogy. Michelle Carey highlights how some critical whiteness scholarship has tended to construct a universal anti-colonial movement with which to express its solidarity. In doing so, it reproduces a strategy of essentialising 'Indigenous' viewpoints and identities into a unified collective, in a common struggle towards decolonisation (Carey 2019: 271-272). This approach might continue to protect white settler power within the Australian academy, because the notion of a homogenous perspective is easier for that power structure to admit and deal with than individual and individualised identities and positions. When we talk about sovereign knowledges and practices, we must look to the needs of localised communities and individual agencies, and what is appropriate to specific relationships. How can I work with my students to frame a nuanced, localised awareness of the creative knowledge systems with which they interact?

Provocations of what creative writing includes, how we know it and who it is for are not cause for emotional hand-wringing or fragile silence on the part of non-Indigenous academics, but rather, a source of disciplinary energy. Non-Indigenous teachers can be refreshed by the promise of situating ourselves as students of the discipline, enlarging the ideas and practices that we love. 


\section{Notes}

[1] This article was developed from a paper presented at the 2020 AAWP Conference at UTS. Thanks to the conference convenors, co-panelists and discussants, and to Peter West for feedback. Sincere thanks to the peer reviewers of this article for their very helpful structural suggestions. I would also like to acknowledge Professor Mark McMillan and my peers in the Bundyi Girri team at RMIT for developing many of the ideas referenced in this article and for transdisciplinary insights. Last but not least, thanks my colleagues in Writing and Publishing at RMIT for sharing and supporting ideas and actions of social change in the discipline. I am grateful to Dr Olivia Guntarik for generously engaging me and my students with the TIMeR app.

[2] Including non-Indigenous authored texts such as Stephen Muecke's works of experimental ethnography; Schlunke, KM 2005 Bluff Rock: Autobiography of a Massacre, Fremantle Press, Fremantle; Gibson, R 2002 Seven Versions of an Australian Badland, UQP, St Lucia; Elvey, A 2017 White on White, Cordite Books, Melbourne; and Krischauff, S 2017 Memory, Place and AboriginalSettler History: Understanding Australians' Consciousness of the Colonial Past, Anthem Press, London; New York. Bruce Pascoe's nonfiction develops this tradition from the viewpoint of dual heritage, for example, Convincing Ground: Learning to Fall in Love with Your Country, Aboriginal Studies Press, Canberra, 2007. For two excellent studies of critical whiteness theory applied to creative practice research, see: Bellette, F 2013 'Interrogating whiteness: A precarious crosscultural/racial creative writing PhD journey', TEXT Journal of Writing and Writing Courses 17, 2 (October); and Razuki, M 2019 'A white woman stories to decolonise (herself)', PhD Thesis, Media and Communication, RMIT University.

[3] See: Griffiths, MR 2018 The Redistribution of Settlement: Appropriation and Refusal in Australian Literary Culture, UWAP. Griffiths builds toward a case for reading for anti-colonial expression:

Reading Australian Literature as Australian Literature begins by putting Aboriginal literary refusals first to produce multidirectional logics that recode and erase the triumphalism of white advocacy... Australian Literature under erasure, no longer settler colonial, wary, resistant to nationalist celebration and the subordination of Indigenous sovereignty as minority within the canonical logic. (Griffiths 2019: 204-205)

\section{Works cited}

Abdullah, J \& E Stringer 1999 'Indigenous Knowledge, Indigenous Learning, Indigenous Research', in JL Kincheloe \& LM Semali (eds) What is Indigenous Knowledge?, Falmer Press, Basingstoke: $143-155$

Anonymous 2019, Course Survey conducted by Author, August 1.

Araluen, E 2017 'Resisting the institution', Overland 227: overland.org.au/previous-issues/issue227/feature-evelyn-araluen/ (accessed 26 March 2020) 
Ball, T 2018 'Indigenous Voices Have Never Been More Important to Australian Literature', The Guardian (23 June): https://www.theguardian.com/books/2018/jun/23/indigenous-voices-have-neverbeen-more-important-to-australian-literature (accessed 10 November 2019)

Carey, M 2019 'Advocating Dialogue or Monological Advocacy? Settler Colonial Theory, Critical Whiteness Studies and the Authentic "Pro-Indigenous" Position', Journal of Australian Studies 43, 3: $268-282$

Christie, M 2006, 'Transdisciplinary Research and Aboriginal Knowledge', The Australian Journal of Indigenous Education 35: 78-89

Christie, M 2009 'Engaging with Australian Indigenous Knowledge Systems: Charles Darwin University and the Yolngu of Northeast Arnhemland', Special Edition: Indigenous Community Engagement, Learning communities: International Journal of Learning in Social Contexts, (December): 23-35

Cole, C 2007 'How the University Workshop Hinders New Writers from Engaging with Ideas', Segue Online Literary Journal: https://opus.lib.uts.edu.au/bitstream/10453/3294/1/2006008734.pdf (accessed 12 December 2019)

Donnelly, D 2012 Establishing Creative Writing as an Academic Discipline, Multilingual Matters, Bristol

Freire, P 2000 Pedagogy of the Oppressed, MB Ramos (trans), Bloomsbury Academic, London Howard, G 1999 'Unravelling Racism: Reflections on the Role of Non-Indigenous People Supporting Indigenous Education', Australian Journal of Adult \& Community Education 35, 3: 229-237

Kincheloe JL \& SR Steinberg 2008 'Indigenous Knowledges in Education: Complexities, Dangers, and Profound Benefits', in NK Denzin, YS Lincoln \& LT Smith (eds), Handbook of Critical and Indigenous Methodologies, Sage: 135-156

Kon-Yu, N 2017 'The Way Things Work: Writing, Diversity, Australia', Peril 30: https:/peril.com.au/back-editions/work-werk-work/the-way-things-work-writing-diversity-australia/ (accessed 5 November 2019)

Leane, J 2016 'Other People’s Stories', Overland 225: https://overland.org.au/previous-issues/issue225/feature-jeanine-leane/ (accessed 3 June 2019)

Martin, L \& B Mirraboopa 2003 'Ways of Knowing, Being and Doing: A Theoretical Framework and Methods for Indigenous and Indigenist Re-search', Journal of Australian Studies 27, 76: 203-214

McMahon, T 2015 'Sickness Country; and Remembering to forget: writing and healing in the Australian novel', PhD Thesis, RMIT University, Melbourne

Moreton-Robinson, A 2015 The White Possessive: Property, Power and Indigenous Sovereignty, University of Minnesota Press, Minneapolis 
Nicoll, F 2004, “"Are you calling me a racist?” Teaching critical whiteness theory in indigenous sovereignty', borderlands 3, 2: http://www.borderlands.net.au/vol3no2 2004/nicoll teaching.htm (accessed 12 February 2020)

Phillips, SR \& C Archer-Lean 2019 'Decolonising the reading of Aboriginal and Torres Strait Islander writing: reflection as transformative practice', Higher Education Research \& Development $38,1: 24-37$

RMIT University 2010, Royal Melbourne Institute of Technology Act: https://www.rmit.edu.au/content/dam/rmit/documents/about/policy/rmit-act-2010.pdf(accessed 23 May 2019)

RMIT University 2019, Dhumba Goorowa Reconciliation Plan 2019-2020:

https:/www.rmit.edu.au/content/dam/rmit/documents/about/indigenous/rmit-dhumbah-goorowa.pdf (accessed 23 May 2019)

Sayed, B 2017 'Literary Production versus Institutional Whiteness', Overland (June): https://overland.org.au/2017/06/literary-production-versus-institutional-whiteness/ (accessed 3

December 2019)

Schulz, S \& J Fane 2015 'A Healthy Dose of Race? White Students' and Teachers' Unintentional Brushes with Whiteness', Australian Journal of Teacher Education 40, 11: 137-154

Sullivan, V 2016 'Confronting Multiplicity: An Interview with Alison Whittaker', Kill Your Darlings (March): https://www.killyourdarlings.com.au/2016/03/confronting-multiplicity/ (accessed 30 January 2020)

TIMeR 2014, Olivia Guntarik, Hugh Davies, Troy Innocent, RMIT University: https://analogueartmap.net (accessed 30 January 2020)

Tombro, M 2016 Teaching Autoethnography: Personal Writing in the Classroom, Open SUNY Textbooks, New York

Tuhiwai Smith, L 1999 Decolonizing Methodologies, Zed Books, London

Whittaker, A 2019 'Keynote', Australasian Association of Writing Programs 24th Annual Conference, UTS Sydney, 25 November

Wolfe, P 2016, Traces of History, Verso, New York 